\title{
Sujeto, transmodernidad, interculturalidad: los estudios humanísticos en la conflictiva y nunca acabada constitución de humanidad $^{1}$
}

\author{
Sujeito, transmodernidade, interculturalidade: estudos humanísticos na \\ constituição conflituosa e nunca terminada da humanidade
}
Subject, transmodernity, interculturality: humanistic studies in the conflictive and never finished constitution of humanity

Yamandú Acosta ${ }^{2}$

\begin{abstract}
Resumen
El artículo responde a una convocatoria que se pregunta por los "estudios humanísticos multidisciplinares", por las relaciones entre "investigación y sociedad" y por los "desafíos y posibilidades de relevancia y visibilidad de la investigación académica". Para hacerlo emplaza a los "estudios humanísticos" en la "constitución de humanidad", la que considera que es "conflictiva y nunca acabada". En un primer punto se refiere a "estudios humanísticos", discierne dos sentidos de "humanidades" y se refiere a la constitución de humanidad a través de tres imperativos categóricos que remiten a Kant y su humanismo crítico, a Marx y su humanismo de la praxis, y a Martí cuyo humanismo nuestroamericano, resignifica los anteriores desde otro lugar.Se exploran algunas claves del humanismo nuestroamericano, se elucida el "nosotros" implícito en Nuestra América de Martí de 1891 al que se considera en términos del "a priori antropológico". En la última sección se procede a una puesta al día en el marco de las perspectivas analítico-crítico-normativas sobre los conceptos Sujeto, Transmodernidad e Interculturalidad. Se muestran las relaciones constitutivas entre estos tres tópicos que se señalan como utópicos, como "ausencias presentes" que vienen operando con creciente presencia en los actuales procesos de transformación del mundo, en cuanto implican humanización. Se concluye reivindicando el papel de los estudios humanísticos desde la academia en su articulación con la sociedad en la constitución de humanidad; una responsabilidad que nos concierne a todos, responsabilidad a la que los "estudios humanísticos" a través de "humanidades" en clave crítica de "ciencia con consciencia" aportan significativamente.
\end{abstract}

Palabras clave: Sujeto; Transmodernidad; Interculturalidad; Humanismo; Humanidades

\section{Resumo}

O artigo responde a uma chamada que pregunta sobre "estudos humanísticos multidisciplinares", sobre as relações entre "pesquisa" e "sociedade" e sobre os "desafíos e posibilidades de relevância e visibilidade da pesquisa acadêmica". Para isso, ele coloca os "estudos humanísticos" na constituçāo de humanidade", que considera "conflituosa e nunca terminada". Em un ponto principal, refere-se a os "estudos humanísticos", discerne dois sentidos de "humanidades" e referese â constituçāo da humanidade a través de três imperativos categóricos que se referem a Kant y seu humanismo crítico, a Marx e seu humanismo da praxis, e Martí, cujo humanismo "nosso-americano" se recusa aos anteriores de outro lugar. Algumas chaves de nosso humanismo americano sāo exploradas, é elucidado o "nós" implicado em Nossa América do Martí de 1891, considerado em

\footnotetext{
${ }^{1}$ Texto correspondiente a la conferencia brindada en el $V^{\circ}$ Encontro Humanístico Multidisciplinar e IV $^{\circ}$ Congresso Latino- Americano em Estudos Humanísticos Multidisciplinares, Universidade Federal do Pampa (UNIPAMPA), Campus Jaguarāo / RS, Brasil, 26 a 28 de noviembre de 2019.

${ }^{2}$ Profesor Titular del Centro de Estudios Interdisciplinarios Latinoamericanos (CEIL) de la Facultad de Humanidades y Ciencias de la Educación y del Instituto de Historia de la Ideas de la Facultad de Derecho,Universidad de la República, Uruguay; yamacoro49@gmail.com
} 
termos de "a priori antropológico".Na última seçāo, é realizada uma actualizaçāo no âmbito das perspectivas analítico - crítico - normativas sobre os conceitos de Sujeito, Transmodernidade e Interculturalidade. Sāo mostradas as relações constitutivas entre esses três tópicos indicados como utópicos, como "ausencias presentes" que operan com crescente presença nos atuais prosessos de transformação do mundo, pois envolvem humanizaçāo. Conclui reivindicando o papel dos estudos humanísticos da academia em sua articulaçāo com a sociedade na constituição da humanidade; uma responsabilidade que diz respeto a todos nós, uma responsabilidade na qual "estudos humanísticos" a través de "humanidades" na chave critica de "ciencia com consciencia" contribuem significativamente.

Palabras-chave: Sujeito; Transmodernidade; Interculturalidade; Humanismo; Humanidades

\begin{abstract}
The article responds to a call that asks about "multidisciplinary humanistic studies", about the relationships between "research and society" and about the "challenges and possibilities of relevance and visibility of academic research". To do so, it places "humanistic studies" in the "constitution of humanity", which it considers to be "conflictive and never finished". At first it refers to "humanistic studies", discerning two senses of "humanities" and refers to the contribution of humanity through three categorical imperatives that refers to Kant and his critical humanism, Marx and his praxis humanism and Martí whose humanism our American, resignifies the previous ones from another place. Some keys of our American humanism are explores, the "we" implicit in Our America of Martí of 1891 is elucidated which is considered in terms of the " $a$ priori anthropological". In the last section, an update is carried out within the framework of the analythical-criticalnormative perspective on the concepts of Subject, Transmodernity and Interculturality. The constitutive relations between these three topics that are indicated as utopic, as "present absences" that are operating with increasing presence in the current processes of transformation of the world, as they involve humanization are shown.

It concludes by claiming the role of humanistic studies from the academy in its articulation with society in the constitution of humanity; a responsibility that concern us all, a responsibility in which "humanistic studies" through "humanities" in critical key of "science with consciousness" contribute significantly.
\end{abstract}

Keywords: Subject; Transmodernity; Interculturality; Humanism; Humanities

\title{
1.Introducción
}

La exposición que aquí se inicia, procura articular en una unidad de sentido, los asuntos que convergen en la convocatoria a la que responde, a saber: los "estudios humanísticos multidisciplinares", las relaciones entre “investigación y sociedad" en específica referencia a este tipo de estudios y la pregunta por los "desafíos de posibilidades de relevancia y visibilidad de la investigación académica".

A los efectos antedichos, se permite emplazar a los "estudios humanísticos" en la "constitución de humanidad", que analítica, crítica o normativamente se postula como su misión específica, la que considera que es "conflictiva y nunca acabada".

En lugar de recurrir al expediente legítimo de pasar revista a "estudios humanísticos" del canon establecido en la tradición de "las humanidades" - esto es, las "disciplinas humanísticas" que aportan las mediaciones disciplinarias para los "estudios humanísticos"- , como es el caso, entre otras, de la Filosofía, la Literatura, la Historia, la Lingüística; prefiere hacerlo a través de la consideración de "Sujeto" , "Transmodernidad" e "Interculturalidad", 
tres tópicos utópicos que operan hoy en la transformación del mundo con horizonte de "humanización", a la que entendemos como "emancipación humana".

Estos tópicos son o pueden ser abordados desde distintas "disciplinas humanísticas", por lo que han sido, son y pueden ser objeto de "estudios humanísticos", que, en lo fundamental, vienen ganado lugar en estos inicios del siglo XXI en esa tarea que nos concierne a todos -académicos y no académicos- que es la "constitución de humanidad".

La "constitución de humanidad" aunque a la luz de lo que nos enseña la Historia sabemos que es "conflictiva y nunca acabada", es un proceso al que -especialmente los académicos en el campo de "las humanidades"- no podemos -en el sentido de que no debemos-, renunciar.

El cultivo de las "disciplinas humanísticas" y la realización de "estudios humanísticos" a través del ejercicio de esas disciplinas no alcanza a legitimarse por la producción de nuevos conocimientos sobre las "humanidades" objeto de nuestras investigaciones y reflexiones; solamente la eventual contribución de esos conocimientos a la "constitución de humanidad" , a la "humanización de la humanidad" y por lo tanto a la "emancipación humana" , configura la última instancia de legitimidad de los "estudios humanísticos".

\section{Estudios humanísticos, humanidades, constitución de humanidad}

Proponemos tener en cuenta dos sentidos del plural de "humanidad", esto es "humanidades".

Por un lado el que se impone a partir del oficio de quienes nos hemos formado en "disciplinas humanísticas" en el marco de las cuales -disciplinariamente, multidisciplinariamente, interdisciplinariamente o transdisciplinariamente- realizamos investigaciones y "estudios humanísticos". Esas disciplinas -Filosofía, Literatura, Historia, Lingüística, etc.- son en su conjunto las "humanidades" que normalmente distinguimos de las ciencias, las técnicas y las artes, las que a su vez incluyen diversas disciplinas.

Pero, por otro lado, "humanidades" puede -y en esta propuesta, quiere- referir a la diversidad de expresiones de lo humano: diversas humanidades en los diversos espacio tiempos de cuyas diferencias hacemos abstracción cuando hablamos, como tradicionalmente lo hacemos, de "la humanidad".

Es por ello que, en lugar de postular como orientación de sentido la "constitución de la humanidad", lo hacemos con la "constitución de humanidad". De esta manera la "humanidad una" incluye a la "humanidad diversa", sin la afirmación inclusiva de la cual, la "humanidad una" quedaría deslegitimada, precisamente como "humanidad". 
A partir de esta última precisión, entendemos que es posible recuperar y postular en su complementariedad dos imperativos categóricos formulados en la modernidad, cuya validez y vigencia se fortalecen al resignificarlos en su conjunción como imperativos categóricos en la transmodernidad ${ }^{3}$ : el formulado por Kant en su Fundamentación de la metafísica de las costumbres de 1785 y el planteado por Marx en su Introducción a la Crítica de la Filosofía del Derecho de Hegel de 1844.

En ambos casos se trata de "imperativo categórico", por lo tanto un imperativo que no es hipotético en cuanto no está sometido a ninguna condición y que tampoco es disyuntivo porque no ofrece alternativas: se debe hacer lo que se debe hacer de un modo incondicionado $\mathrm{y} \sin$ alternativa.

Dice la segunda fórmula del imperativo categórico de Kant: “obra de tal modo que uses la humanidad, tanto en tu persona como en la persona de cualquier otro, siempre como un fin al mismo tiempo y nunca solamente como un medio "(KANT, 1967, p. 84).

Se trata, en la línea kantiana de la ética de la intención, de un imperativo que rige la conducta en el ámbito de la subjetividad. En su fórmula se descuenta que la relación instrumental con "la humanidad" -sea en la propia persona, sea en "la persona de cualquier otro", esto es que sea tomada "como un medio" es un uso que se da de hecho y, tal vez, sin excepciones. No obstante la facticidad o presunta inevitabilidad del uso instrumental de "la humanidad" como "un medio", lo que debe hacerse siempre y en toda circunstancia además, es obrar usando "la humanidad" "siempre como un fin al mismo tiempo".

Obrar usando la humanidad -en mí o en otro- además de "como un medio", "como un fin al mismo tiempo", nos hace trascender la racionalidad instrumental de medios en la racionalidad práctica de fines para la que la humanidad en la persona es, antes que todo, un fin en sí mismo: vale incondicionalmente y no debe ser sustituido por otro fin.

En cuanto a la fórmula del imperativo categórico de Marx, enuncia:

\begin{abstract}
La crítica de la religión desemboca en la doctrina de que el hombre es el ser supremo para el hombre y por lo tanto en el imperativo categórico de acabar con todas las situaciones que hacen del hombre un ser envilecido, esclavizado, abandonado, despreciable (MARX, 1994, p. 77).
\end{abstract}

\footnotetext{
${ }^{3}$ Usamos y analizamos "transmodernidad" desde la caracterización acuñada por Enrique Dussel (DUSSEL, 1992, p. 245-250) y, eventualmente más allá de esa caracterización, pero claramente en su espíritu y nunca contra ese espíritu con que Dussel la ha propuesto al cumplirse 500 años del "encubrimiento del otro", invisibilizado en el mito de la modernidad como descubrimiento de América. Volveremos sobre "transmodernidad" para analizar el concepto-categoría y sus implicaciones analíticas, críticas y normativas, en la última sección de esta exposición.
} 
Complementariamente a Kant -esta es nuestra interpretación- y por lo tanto a la dimensión de la subjetividad en la que el filósofo de Königsberg pone el acento; el renano de Tréveris lo hace con la dimensión de la objetividad: frente "situaciones que hacen del hombre un ser envilecido, esclavizado, abandonado, despreciable", se trata de "acabar con ellas" objetivamente por cuanto son deshumanizantes, más allá de la orientación del obrar en el sentido de usar "la humanidad" "siempre y al mismo tiempo como un fin".

Si las "situaciones que hacen del hombre un ser envilecido, esclavizado, abandonado, despreciable" en cumplimiento del imperativo categórico son eliminadas de la faz de la Tierra, entonces podríamos tener eventualmente situaciones que hacen del hombre un ser ennoblecido, liberado, amparado, respetable.

Al "acabar" en cumplimiento del imperativo categórico con las situaciones $-\mathrm{O}$ "relaciones", según otras traducciones al español del texto de Marx ${ }^{4}$ - deshumanizantes denunciadas por Marx, no hay ningún automatismo que asegure las situaciones -o "relaciones" humanizantes antónimas a aquellas deshumanizantes que nos hemos permitido identificar. No obstante, sin lugar a dudas se habrán generado mejores condiciones para que la "humanización" de "las humanidades" que es condición de la "humanización" de "la humanidad", sea posible.

En el argumento de Marx, su imperativo categórico de la acción concreta en los estrictos términos de un humanismo de la praxis que complementa resignificándolo al imperativo categórico de la intención moral del humanismo crítico de Kant, se deriva de "la doctrina de que el hombre es el ser supremo para el hombre".

Que "el hombre es el ser supremo para el hombre" es el criterio para el discernimiento de las religiones y sus dioses -celestiales o terrenales-: aquellas que no ponen al "hombre" en el lugar del "ser supremo" -esto es, en el lugar de Dios-, son idolatrías deshumanizantes.

El ejemplo más actual y omnipresente es la idolatría del mercado que la religión neoliberal ha impuesto globalmente al colonizar globalmente las subjetividades, haciendo ver a las relaciones mercantiles totalizadas como "relaciones que hacen del hombre un ser ennoblecido, liberado, amparado, respetable", cuando en realidad son objetivamente "relaciones que hacen del hombre un ser envilecido, esclavizado, abandonado, despreciable".

\footnotetext{
${ }^{4}$ Hinkelammert toma la traducción del imperativo categórico de Marx que presenta la edición en español del libro de Erich Fromm Marx y su concepto del hombre, FCE, México, 1964, p.31-32. Esa traducción refiere al "imperativo categórico de echar por tierra todas las relaciones en que el hombre sea un ser humillado, sojuzgado, abandonado y despreciable" (HINKELAMMERT, 2007, p. 22.
} 
Obramos de manera dominante usando la humanidad en nuestra persona o en la de otros siempre solamente como un medio y nunca como un fin: la humanidad -sea en nosotros o en los otros- no pasa de ser un insumo para un producto que responde a la racionalidad instrumental del mercado: la humanidad reducida a medio para un fin que es opuesto a su realización como humanidad; reducida a mercancía, deja de valer incondicionalmente; su valor lo fija el mercado.

El totalitarismo del mercado vigente pone en el lugar del ser supremo al mercado, desplazando de ese lugar al ser humano en una lógica en la que en lugar de ser el mercado para el ser humano, el ser humano es para el mercado (Hinkelammert, 2018): la humanidad del ser humano es solamente "un medio" y las situaciones o relaciones en que vive hacen de él "un ser envilecido, esclavizado, abandonado, despreciable".

Es ese desafiante contexto en que las "humanidades" se encuentran sometidas a negación, sometimiento o invisibilización de su "humanidad" reducida a "medio", que "las humanidades" o "disciplinas humanísticas" a través de sus "estudios humanísticos" tienen un relevante papel crítico-constructivo a cumplir en la "constitución de humanidad".

\section{EI humanismo nuestroamericano}

Hemos hecho referencia a un "humanismo crítico" en relación a Kant y a un "humanismo de la praxis" en relación a Marx.

No concebimos ni ejercemos las "disciplinas humanísticas" ni los "estudios humanísticos" por la mediación de aquellas en sí mismas o en sus eventuales sinergias multidisciplinarias, interdisciplinarias o transdisciplinarias, sino al interior de un "humanismo".

Eventuales excesos o restricciones del primer humanismo de la modernidad, encuentran en el "humanismo crítico" de Kant -en su especificidad de "filosofía crítica" o "criticismo"- y en el "humanismo de la praxis" de Marx, sentidos válidos y vigentes de ese humanismo de la modernidad que llega hasta nosotros, que hacemos nuestro y en el que nos inscribimos.

Pero, en nuestro caso - el mío muy en particular- no lo hacemos en una línea de continuidad con el kantismo y/o con el marxismo, sino desde otro lugar que es de recepción pero también de enunciación y propuesta, que se deja interpelar pero también interpela -desde ese otro lugar- a ese humanismo eurocéntrico de la modernidad: el humanismo nuestroamericano de la transmodernidad.

El "humanismo nuestroamericano" resignifica al "humanismo crítico" de Kant y al "humanismo de la praxis de Marx" que a su vez han resignificado al humanismo clásico del 
Renacimiento europeo desde y sobre la referencia tópico - utópica paradigmáticamente formulada por José Martí en 1891 como Nuestra América ${ }^{5}$.

El título martiano inevitablemente se sostiene sobre un implícito "nosotros".

Ese "nosotros" implícito tenía una dimensión tópica que Martí registra en 1891 y con transformaciones a lo largo del tiempo, la sigue teniendo en este espacio territorial que incluye las islas del Caribe y el espacio subcontinental desde el Río Bravo hasta el extremo sur del continente americano llegando hasta este 2019, y la seguirá teniendo en el futuro que, como sabemos, es contingente.

No obstante sus transformaciones a lo largo de ciento veintiocho años de historia, el "nosotros tópico" se ha caracterizado justamente por su no constitución como efectivo "nosotros" en términos de plenitud.

Ese "nosotros" en términos de plenitud inalcanzable, acompaña como "nosotros utópico" al "nosotros tópico" al que acicatea en el sentido de la superación de sus defectos y falencias sobre la referencia de esa plenitud inalcanzable en que consiste.

Martí en Nuestra América da cuenta del "nosotros tópico" a la luz del "nosotros utópico".

No aporta una mera descripción empírica a partir de una constatación de los hechos de talante positivista, sino una comprensión analítico-crítico-normativa.

En ella, ese "nosotros tópico" defectivo puede transformarse con sentido de superación de su ser defectivo por la orientación crítico-regulara del "nosotros utópico" que ha tenido en la defectividad del "nosotros tópico" sus condiciones de posibilidad

En nuestra América, la identidad de la población colonizadora ibérica y de sus descendientes mestizos y criollos, "identidad barroca" o "híbrida" es de suyo problemática en la configuración de un "nosotros".

Se suma a esa condición problemática de la identidad de mestizos y criollos -y esto es fundamental en la no constitución del nosotros tópico-, la invisibilización, negación o exclusión de indios y negros: pueblos originarios y afrodescendientes.

\footnotetext{
${ }^{5}$ No se pretende en esta tesis que José Martí esté considerando explícitamente los imperativos categóricos de Kant y Marx consignados. No nos consta que tuviera conocimiento de esas formulaciones. No obstante, en cuanto tanto Kant como Marx expresan filosóficamente a la modernidad, además de trasuntar ambos eurocentrismo; si acordamos en principio con Pedro Pablo Rodríguez que Martí en Nuestra América es un "contramoderno" (RODRÍGUEZ, 2011, p. 1) o, más aún si proponemos -como es nuestro caso- tomado el concepto "transmodernidad" de Dussel, que es un "transmoderno", en la perspectiva contramoderna o transmoderna de la modernidad de Martí, queda contenida la interpelación a los imperativos categóricos con que se expresa la modernidad burguesa o la modernidad anti-burguesa, ambas eurocéntricas.
} 
Los primeros por su sola existencia en el territorio que habitamos serían sus legítimos ocupantes.

Los segundos, esclavizados y reterritorializados contra su voluntad en estas tierras, sumarían al sometimiento e invisibilización de los indios el suyo específico.

Sometimiento e invisibilización impuesto a unos y otros por el colonizador europeo primero y por el dominador criollo, después.

Así Martí registra en su Nuestra América nuestra "identidad barroca" o "hibrida" que incluye "los calzones de Inglaterra", "el chaleco parisiense", "el chaquetón de Norte-América" y "la montera de España” (MARTÍ, 1992, p. 484).

Pinta poéticamente la exclusión de indios y negros por parte de ese no constituido excluyente e imposible "nosotros tópico" con sus tensiones entre vida campesina y vida urbana:

El indio, mudo, nos daba vueltas alrededor, y se iba al monte, a la cumbre del monte a bautizar a sus hijos. El negro, oteado, cantaba en la noche la música de su corazón, solo y desconocido, entre las olas y las fieras. El campesino, el creador, se revolvía, ciego de indignación, contra la ciudad desdeñosa, contra su criatura. Éramos charreteras y togas, en países que venían al mundo con la alpargata en los pies y la vincha en la cabeza (MARTí, 1992, p. 484-485).

Inmediatamente, Martí aporta -siempre en prosa poética- la que proponemos identificar como la fórmula del "imperativo categórico nuestroamericano".

Esta fórmula, es válida para los contextos anteriores a 1891 en nuestra América a los que el autor cubano se refiere, e igualmente válido para los contextos posteriores, incluido el actual y, por lo tanto, además de válida, vigente en una perspectiva instituyente ${ }^{6}$ :

El genio hubiera estado en hermanar, con la caridad del corazón y con el atrevimiento de los fundadores, la vincha y la toga, -en desestancar al indio,- en ir haciendo lado al negro suficiente,-en ajustar la libertad al cuerpo de los que se alzaron y vencieron por ella. (MARTÍ, 1992, p. 485).

Esta que caracterizamos como fórmula del "imperativo categórico nuestroamericano" expresa la clave del "nosotros nuestroamericano" en su dimensión utópica que emerge desde la dimensión tópica, aportando los criterios para su superación: fraternidad, igualdad y libertad, pero no solamente dentro del horizonte de la modernidad eurocéntrica, sino más allá de ellos en el horizonte de la transmodernidad nuestroamericana.

\footnotetext{
${ }^{6}$ Se trata aquí de validez y vigencia en referencia a un ethos cultural, tal como presenta estos conceptos Mario Sambarino cuando caracteriza como culturalmente vigente "el orden de lo que es según valores" y como culturalmente válido "el orden de lo que es valioso que sea" (SAMBARINO, 1959, p 220 y ss.).

Esta distinción le permite a Sambarino señalar que es posible la vigencia de órdenes culturales que sean válidos, así como la de los que no lo sean. También la concepción de órdenes culturales válidos que no hayan estado ni estén vigentes.

A partir de estas reflexiones de Sambarino, nos hemos permitido proponer para un orden válido "que es valioso que sea", que este puede tener una vigencia instituida o haberla tenido en algún pasado, pero que en caso de no haberla tenido antes y no tenerla en el presente, puede -en el pasado y el presente- dada su validez, mantener o incrementar una vigencia instituyente.
} 
En la dimensión tópica de nuestra América, primaban en 1891 y continúan dominando hoy entre nosotros ciento veintiocho años después, la hostilidad, la desigualdad y el sometimiento.

Emerge frente a ella y como respuesta a su anti-humanismo, el "nosotros utópico nuestroamericano" con potencial crítico-regulador, desnaturalizador e historizador y anticipador de un futuro otro posible ${ }^{7}$, tal como Martí lo anticipa en Nuestra América, portador de fraternidad, igualdad y libertad.

Se trata de fraternidad, igualdad y libertad otros respecto de la modernidad burguesa eurocéntrica que los ha construido para sí sobre la base de su negación objetiva para las alteridades, aunque ha procurado legitimar esa objetiva negación a través de la promesa trasladada una y otra vez al futuro, de su realización también para las alteridades.

Esas alteridades de la modernidad burguesa eurocéntrica incluyen a las de nuestra América, aunque no se reducen a ellas. Hay alteridades que están fuera de la fraternidad, la igualdad y la libertad modernas burguesas eurocéntricas, también dentro de Europa -las clases y comunidades sometidas- y más allá de Europa -entre las cuales nuestra América-, las naciones sometidas a la acción colonial, imperial o neocolonial y neo-imperial relocalizada en los EEUU.

Fraternidad -en primer lugar- al "hermanar, con la caridad del corazón y con el atrevimiento de los fundadores, la vincha y la toga". Igualdad -en segundo lugar- al "desestancar al indio" e "ir haciendo lado al negro suficiente". Libertad -finalmente- al "ajustar la libertad al cuerpo de los que se alzaron y vencieron por ella".

\footnotetext{
${ }^{7}$ Arturo Andrés Roig distingue entre género utópico y "función utópica del discurso". Esta función la cumplen tanto las utopías narrativas - paradigmáticamente Utopía de Moro de 1516- como también discursos ideológicos, políticos, religiosos, filosóficos o aún científicos. El ejercicio de la función utópica en el proceso de enunciación implica la constitución de un sujeto, constitución que queda objetivada en lo enunciado. Al interior de esa función utópica del discurso, Roig distingue analíticamente una "función crítico-reguladora" (hace la crítica de lo dado y brinda orientación para la superación de los problemas que lo dado presenta), una "función liberadora del determinismo legal" (historiza o desnaturaliza el orden que la dominación ha naturalizado) y una "función anticipadora de futuro" (anticipa un futuro-otro, que no es entonces una mera extensión del presente, sino que implica una ruptura con él) (ROIG, 1987, p.3-97).

A partir de los señalamientos y desarrollos de Roig, continuándolos y complementándolos, Estela Fernández explicita una función de síntesis, a su juicio implícita en los planteamientos de Roig:" la función constitutiva de formas de subjetividad" (a través del ejercicio de la función utópica -crítico-reguladora, liberadora del determinismo legal, anticipadora de futuro- el sujeto se constituye en su condición de sujeto de discurso (FERNÁNDEZ, 1995, p. 42-47).

En sintonía con Roig y Fernández, podemos señalar que el sujeto del discurso se constituye como tal al interior de un universo del discurso. Este universo se constituye a su vez al interior de un universo social, cuyas tensiones expresa en su dimensión específica.

La relación discurso - sociedad es de doble vía: el discurso opera en la sociedad en su conjunto, así como esta lo hace en el discurso. En una y otra dirección hay mediaciones que explican las interpenetraciones posibles entre discurso y sociedad. Estas consideraciones aportan al tema de las relaciones entre "investigación y sociedad" que hace parte de la convocatoria en la que las presentes reflexiones se inscriben.
} 
El lema de la revolución francesa, que siendo originariamente una revolución popular, termidor mediante, se transforma en revolución burguesa (Hinkelammert, 2018, p. 105-141): "libertad, igualdad, fraternidad"; se ve transformado en su orden de enunciación y por ello plausiblemente de fundamentación en el que podría ser el lema de la revolución transmoderna desde nuestra América más allá de los límites de la revolución francesa y burguesa: fraternidad, igualdad, libertad.

Es imperativo que los seres humanos se relaciones como hermanos, para que a través de esa fraternidad fundante, generen las condiciones para fundar y sostener la igualdad y, sobre los fundamentos de la fraternidad entre todos y la igualdad de todos, establecer la condiciones de posibilidad para la libertad de cada uno que es la condición de la libertad de todos y la libertad de todos que es la condición de la libertad de cada uno.

Pero el criterio para la libertad de todos y de cada uno es "el cuerpo de los que se alzaron y vencieron por ella"; esto es, quienes practicando la fraternidad construyeron la igualdad -allí y cuando ni una ni otra estaban vigentes- y con ello hicieron posible la libertad para cuya conquista pusieron el cuerpo.

No se trata aquí de "las leyes de la libertad" como criterio de la libertad abstracta de la modernidad eurocéntrica, sino del "cuerpo" -y por lo tanto de las necesidades de reproducción de la vida-, de quienes excluidos por "las leyes de la libertad" de un mundo que les imponía su dominación, "se alzaron" en la conquista de la libertad y "vencieron por ella".

Frente a la libertad abstracta de la modernidad eurocéntrica, la libertad concreta de la transmodernidad nuestroamericana.

La interpelación de aquella libertad abstracta por esta conquista de la libertad concreta, aporta no solamente a la construcción de libertad en nuestra América, sino en el mundo todo. No se trata de reeditar el universalismo falso o abstracto del eurocentrismo, ahora como americano-centrismo.

Arturo Andrés Roig elabora filosóficamente la constitución de ese "nosotros utópico nuestroamericano" normativamente orientado por y hacia la fraternidad, la igualdad y la libertad.

Frente al "nosotros tópico" en nuestra América que ante toda alteridad manifiesta hostilidad, genera, profundiza e intenta consolidar desigualdad y sometimiento, el "nosotros utópico" se constituye.

Transforma su condición de alteridad negada en afirmación de su dignidad a través del ejercicio del que Roig, con Kant y Hegel aunque más allá de Kant y Hegel y eventualmente contra ellos, identifica como el "a priori antropológico", el que implica "«querernos a 
nosotros mismos como valiosos» y consecuentemente un «tener como valioso el conocernos a nosotros mismos»" (ROIG, 1981, p. 11), también "ponernos para nosotros y valer sencillamente para nosotros" (ROIG, 1981, p. 16).

Sin desarrollar aquí en toda su riqueza la cuestión del "a priori antropológico" en Roig, nos alcanza con destacar que es un ejercicio por el que diversas "humanidades" -en el primer sentido en que hemos consignado este plural de "humanidad", se afirman precisamente en la dignidad humana -igualmente valiosa a cualquier otra- que se reconocen en ese autoreconocimiento de un "nosotros" como acto de autoconstitución en que lo utópico emerge en el contexto de lo tópico para transformarlo.

Pero no solamente somos valiosos nosotros mismos en nuestra diversidad e identidad como "humanidades" en relación con otras "humanidades" tanto al interior como al exterior de nuestro "nosotros".

Concomitantemente, el "tener como valioso el conocernos a nosotros mismos" dice acerca del valor de las "humanidades" como disciplinas.

En consecuencia dice también del valor de los "estudios humanísticos" por los que las "disciplinas humanísticas" aportan al conocimiento de la "humanidad" de nuestra "humanidad", no solamente por que puedan dar cuenta de su ser, sino también y fundamentalmente de su valer.

Conocimiento de nuestro ser y de nuestro valer, que en ese ejercicio del "a priori antropológico", nos incluye precisamente a todos quienes hacemos parte de ese nosotros que en la tensión tópico-utópica se constituye: “...la razón de todos en las cosas de todos y no la razón universitaria de unos sobre la razón campestre de otros” (MARTÍ, 1992, p. 484).

Las relaciones entre "investigación y sociedad" -por las que la convocatoria a la que este texto ha intentado aportar algunas respuestas se ha preguntado, en particular cuando de lo que se trata es del conocimiento de nosotros mismos en el que tanto representantes de "la razón campestre" como de "la razón universitaria" estamos concernidos-, resultan de evidente y sinérgica complementariedad.

\section{Sujeto, Transmodernidad, Interculturalidad}

Dedicaremos este último tramo de nuestra exposición a la consideración de los tres tópicos utópicos que en estos inicios del siglo XXI están operando -a nuestro juicio con creciente centralidad - en la transformación del mundo y, en cuanto el ser humano como es sabido, es un ser en el mundo, en la transformación del ser humano mismo en el sentido de "constitución de humanidad". 
Comenzaremos destacando la íntima y constitutiva conexión entre los tres tópicos, para luego hacer una presentación analítica de cada uno de ellos dentro de los límites que razonablemente aconseja la presente exposición.

Que el ser humano sea sujeto es una idea que nace con la modernidad. Puede decirse con total reciprocidad que la modernidad mace de la mano de la idea de que el ser humano es sujeto. No obstante en el mismo proceso -el de la modernidad- por el cual la humanidad se autoafirma como sujeto genera mediaciones para esa autoafirmación que terminan desplazándola de ese lugar en que se ha ubicado ${ }^{8}$.

Centralmente las grandes institucionalidades de la modernidad, el Estado y el mercado -ambas creaciones humanas mediadoras para la autoafirmación del ser humano como sujeto- , usurpan en distintos procesos de complementariedad el lugar del sujeto, hasta que hoy en el marco de un totalitarismo del mercado globalizado, lo han desplazado totalmente.

Surge como consecuencia que para que el lugar que la modernidad ha conquistado para el ser humano no se pierda, es necesario superar las razones por las que la lógica de la modernidad lleva a la negación de su propia conquista.

Allí cobra cuerpo la transmodernidad, como condición de posibilidad de la modernidad y como proyecto para superarla, no como lo ha pretendido la posmodernidad que en realidad, lejos de superarla, la ha profundizado en sus ejes nihilista y anti-universalista ${ }^{9}$.

En la recuperación y afirmación de la transmodernidad se juega la recuperación y afirmación del ser humano como sujeto.

Ya no se tratará del sujeto moderno -ni del individuo posmoderno-, sino del sujeto transmoderno que pretendidamente encontrará en las relaciones e instituciones de la transmodernidad condiciones para su afirmación sin su desplazamiento.

La transmodernidad en cuanto objetividad de situaciones, relaciones e instituciones, encuentra en el sujeto transmoderno, justamente un sujeto -mucho más que un actor- que en condición de tal, además de afirmar las relaciones, situaciones e instituciones de la transmodernidad, que son humanizantes, no delega en los eventuales automatismos de éstas esa responsabilidad de humanización.

Tal vez un aprendizaje fundamental que la transmodernidad puede tener de la modernidad, sea el no incurrir en el utopismo del sujeto moderno de apostar a instituciones de

\footnotetext{
${ }^{8}$ Este argumento atraviesa las numerosas obras de Franz J. Hinkelammert, entre ellas, las que citamos expresamente en este texto. De la obra de este autor que venimos trabajando desde 1992, también en diálogo con él, tomamos el argumento, que compartimos.

${ }^{9}$ La posmodernidad como profundización de la modernidad y no como su superación, está muy bien y complementariamente argumentada por Hinkelammert (HINKELAMMERT, 1991, p. 81-101 y DUSSEL, 1992, p. 245-250). Esas dos fuentes inspiran centralmente nuestro análisis.
} 
funcionamiento perfecto que por sus propios automatismos resuelvan los problemas de la vida humana cuando en realidad los aumentan al volverse en contra de la propia vida humana, sino recuperar el realismo a través de cuyo sentido estratégico, el ser humano no pierde, delega o enajena la posición protagónica de sujeto en el ejercicio de la política como arte de lo posible (HINKELAMMERT, 1990, p. 19-29).

El monoculturalismo de la modernidad construye un falso universalismo desde que excluye las alteridades a la cultura moderno-occidental; el multiculturalismo de la posmodernidad, denuncia por abstracto y falso a aquél monoculturalismo frente al que propone la lógica de la fragmentación del multiculturalismo, que ya es un explícito antiuniversalismo.

La perspectiva de la interculturalidad quiere ser una alternativa humanizante para todas las "humanidades" en la "constitución de humanidad" en términos de un universalismo concreto, superador del universalismo abstracto de la modernidad y del antiuniversalismo de la posmodernidad.

El sujeto o el ser humano como sujeto que hoy afirmamos desde el humanismo nuestroamericano como lugar de enunciación, no es ningún sujeto sustancial -en el sentido cartesiano- ni tampoco a priori en el sentido kantiano, ni sujeto de la historia en el sentido de alguna lectura de Marx, por la que el proletariado lo sería inexorablemente; no es en definitiva ninguna presencia sino una ausencia que se hace presente como ausencia, tal como lo explica magistralmente Hinkelammert:

\begin{abstract}
El llamado a ser sujeto se revela en el curso de un proceso. Por eso, el ser sujeto no es un a priori del proceso, sino resulta como su a posteriori. El ser humano como sujeto no es ninguna sustancia y tampoco un sujeto trascendental a priori. Se revela como necesidad en cuanto resulta que la inercia del sistema es autodestructiva. Se revela, entonces, que el ser sujeto es una potencialidad humana y no una presencia positiva. Se revela como una ausencia que grita y que está presente, pero lo es como ausencia. Como tal la ausencia solicita. Hacerse sujeto es responder a esta ausencia positivamente, porque esta ausencia es, a la vez, una solicitud. Se trata de una respuesta positiva a la ausencia, sin eliminarla como ausencia. Responde. En este sentido, el ser humano es parte del sistema en cuanto actor o individuo calculante. En cuanto sujeto está enfrentado al sistema, lo trasciende (HINKELAMMERT, 2003, p. 496).
\end{abstract}

En este pasaje, Hinkelammert parte de una situación actual que -también con él- hemos caracterizado como totalitarismo del mercado.

Todas las personas y todas las sociedades en razón de la lógica totalizante de ese totalitarismo del mercado de vigencia planetaria global, somos partes de ese sistema al interior del mismo: actores en el mercado que para vivir en ese sistema actuamos como individuos calculantes en términos de costo y beneficio. 
En cambio, en cuanto sujetos estamos enfrentados a ese sistema al que trascendemos en la modalidad de una trascendentalidad inmanente.

Estamos dentro del sistema totalizante y totalitario (como actores e individuos calculantes) por lo que solamente podemos ver lo que nos deja ver y podemos elegir lo que nos deja elegir; como actores e individuos calculantes somos funcionales al mercado que se encuentra -porque allí lo hemos puesto- en el lugar del ser supremo.

Como sujetos trascendemos al sistema que solamente puede encerrarnos dentro de sus límites en la condición de actores o individuos calculantes, no en la de sujetos.

Por ello, justamente, la condición de sujeto es una ausencia presente como ausencia en el individuo funcional al sistema.

Cuando el individuo experimenta que la inercia del sistema al que es funcional lo amenaza, entonces se hace presente como ausencia la condición de sujeto. Claramente, el ser humano como sujeto no es un a priori del proceso, sino un a posteriori por reacción a la destructividad del sistema.

Ese ser humano como sujeto, que no es ninguna "sustancia", que tampoco es "ningún sujeto trascendente a priori", no es claramente el sujeto que ha identificado la modernidad en sus distintas versiones filosóficas.

En cuanto puede trascender al sistema totalitario, puede constituirse, pero claramente de un modo a posteriori sin por ello eliminar su condición de ausencia.

Convergentemente, aunque sin proponerse converger con este planteamiento, convergencia que no es sin embargo casual, el a priori antropológico a través de cuyo ejercicio el "nosotros", es decir el sujeto en clave colectiva histórico-social se constituye según Arturo Roig, es justamente un a priori que de un modo contingente se manifiesta $a$ posteriori de una experiencia de negación en la perspectiva alternativa de afirmación.

Frente al sujeto sustancial, a priori, el sujeto que "es" de la modernidad; tenemos el sujeto contingente, a posteriori, el sujeto que "no es" en la modernidad, sino que se constituye al ejercer el a priori antropológico que le permite trascenderla como sujeto, tanto como al mercado totalitario al cual la modernidad aporta sus fundamentos culturales.

Este sujeto del que el "humanismo nuestroamericano" que va de Martí a Roig y con el que Hinkelammert coincide desde un humanismo de la praxis en clave de transmodernidad a cuyo interior se inscribe el humanismo nuestroamericano, exhibe sus señas de identidad.

Éstas lo contraponen al sujeto de la modernidad en cualquiera de sus versiones, así como también al individuo de la posmodernidad en el que la condición de sujeto se ha disuelto en la hipercrítica nihilista. 
Podría en consecuencia -a nuestro juicio-, asumir legítimamente la condición de "sujeto de la transmodernidad" o "sujeto transmoderno".

Se impone una presentación analítica de "transmodernidad", palabra que ya hemos usado sin analizarla con un mínimo detalle y que ya hemos contrapuesto como palabra, pero también como realidad por ella mentada, a la "modernidad" y a la "posmodernidad".

A partir de una básica presentación analítica del concepto de "transmodernidad", podremos presentar los conceptos de "sujeto de la transmodernidad" o "sujeto transmoderno" que estamos proponiendo.

El concepto de "transmodernidad", como hemos adelantado, lo entendemos y utilizamos dentro del horizonte de sentido con que Dussel lo ha propuesto en 1992 en su libro 1492 El encubrimiento del otro. El origen del mito de la modernidad (DUSSEL, 1992, p. 245-250).

Sintéticamente significa que, a diferencia de la modernidad que afirma una razón autocentrada y de la posmodernidad -que no es sino la profundización del sentido negativo o mítico de la modernidad, que afirma la irracionalidad que es la contracara de aquella racionalidad excluyente-, la Transmodernidad "ataca como irracional a la violencia de la Modernidad, en la afirmación de la razón del Otro" (DUSSEL, 1992, p. 246).

Ella consiste en el descentramiento de la razón sobre la referencia de las alteridades. Al afirmar "la razón del otro" se nos abre la posibilidad para -desde ella- afirmarnos no ya como modernidad o como posmodernidad, sino como transmodernidad.

Pero transmodernidad no es una cultura que viene después de la posmodernidad, la que tampoco es una cultura que venga después de la de la modernidad.

La transmodernidad es una trascendentalidad inmanente a la modernidadposmodernidad, nombra una realidad alternativa efectiva, posible y deseable que la racionalidad autocentrada de la modernidad y la irracionalidad de la posmodernidad han invisibilizado y negado.

En cuanto es condición de posibilidad de aquéllas las trasciende; hacia el pasado como aquello que la modernidad (des) califica como pre-modernidad y hacia el futuro como horizonte de un proyecto alternativo al de la modernidad.

Y alternativo a la posmodernidad, que niega todo proyecto. En la transmodernidad las alteridades negadas por la modernidad y su profundización posmoderna -seres humanos, culturas y naturaleza, en sus diversidades-, se transforman ahora en el criterio, referencia o última instancia para la construcción del orden. 
Proponemos que así como hay un sujeto moderno o de la modernidad que es sustituido por el individuo posmoderno o de la posmodernidad, hay un sujeto transmoderno o de la transmodernidad que es negado, oprimido e invisibilizado por aquél sujeto y aquél individuo de los que es su condición de posibilidad.

Es su condición de posibilidad en cuanto trascendentalidad inmanente a ellos.

Justamente en esa crisis de la modernidad que es la posmodernidad, emerge constituyéndose desde su ausencia que se hace presente como tal ausencia.

En el proceso de su constitución, constituye a la transmodernidad como horizonte e idea reguladora orientadora de transformaciones.

Transformaciones no ya solamente en la perspectiva de una superación crítica del capitalismo, sino de la sociedad moderna-posmoderna-occidental, en cuyas claves culturales, este modo de producción-destrucción globalizado y totalizado como racionalidad mercantil, encuentra sus fundamentos culturales.

Liberación desde la transmodernidad -y hacia ella- es un más allá de la emancipación de la modernidad y no simplemente una profundización o extensión de la modernidad como es el caso de la posmodernidad.

La liberación transmoderna hace factible una efectiva universalización de la emancipación humana en la diversidad de sus expresiones no excluyentes.

Esta universalización de la emancipación humana, implica una liberación no solamente de las orientaciones anti-emancipatorias y anti-universalistas propias del sentido mítico de la modernidad, sino también de las orientaciones emancipatorias y universalistas de la modernidad.

Al ser autocentradas, las orientaciones emancipatorias y universalistas de la modernidad, quedan condenadas a emancipación y universalismo de la mismidad.

Frente a esta emancipación y humanismo abstractos en cuanto limitados, la liberación transmoderna o la Transmodernidad como liberación, al habilitar la emancipación desde la referencia a la alteridad, lo hace con todas las mismidades que tengan su referencia en todas las alteridades.

Una humanidad constituida desde la acción constituyente de humanidades diversas que al tener en las humanidades otras su referencia, sin sacrificar su diferencia y por lo tanto su identidad por el despliegue en los territorios de estilos de vida que son compatibles con los de todas y cada una de las otras humanidades, hacen posible una humanidad una y diversa en la lógica de un mundo en el que todas -naturaleza incluida-, pueden vivir. 
La emancipación y el universalismo concretos contenidos en el espíritu transmoderno de la categoría de liberación, tiene su correlato en el espíritu liberador de la categoría de transmodernidad. ${ }^{10}$

Pasaremos ahora a detenernos en el tópico de la Interculturalidad.

En referencia a las transiciones políticas en lo que hace a los cambios de gobierno en democracia, se ha comparado la transición con una carrera de postas.

Así como en la carrera de postas hay un trayecto en el que quien entrega el testimonio y quien lo recibe corren juntos a los efectos de asegurar la mejor continuidad al proceso de transferencia de ese testimonio en beneficio de mantener la velocidad que optimice el resultado, así en la transición de la modernidad a la transmodernidad hay un trayecto -en el cual estamos con creciente visibilidad desde 1992 en el contexto de la conmemoración de los 500 años del descubrimiento de América, que Dussel discierne como "encubrimiento del otro" - en el cual modernidad y transmodernidad, corren juntas.

Pero justamente allí, para este caso, la analogía se termina.

La modernidad no quiere entregar el testimonio a la transmodernidad, sino que aspira a mantenerlo en sus manos, superar a la transmodernidad y por su exclusivo y excluyente protagonismo proyectarse velozmente hacia la meta a los efectos de ganar la carrera...que es una carrera sin sentido.

La transmodernidad por su parte, no quiere recibir el testimonio de la modernidad, que lo es de los valores que justamente la transmodernidad quiere superar y, además, no se proyecta linealmente en el espacio-tiempo a ganar una carrera, sino que apunta a disuadir de esa proyección acelerada hacia delante de la humanidad que bajo la promesa de la victoria, amenaza conducirla a su auto-destrucción, en una victoria pírrica.

Para hacer posible esa transición, ni el monoculturalismo de la modernidad ni el multiculturalismo de la posmodernidad son adecuados.

El monoculturalismo de la modernidad es autocentrado y constitutivamente refractario a la consideración y reconocimiento de la alteridad del otro en la legitimidad de su específica forma de vivir la humanidad a través de la mediación de su humanidad.

En el multiculturalismo de la posmodernidad ese autocentramiento se ha fragmentado en múltiples "nosotros" que encuentran necesaria y suficiente la afirmación de su humanidad

\footnotetext{
${ }^{10}$ La preferencia por liberación respecto de emancipación sobre los fundamentos que se ha ofrecido, atraviesa toda la obra de Dussel, su filosofía de la liberación. De esa obra y en particular de la que hemos citado en nuestra exposición hemos tomado liberación como concepto preferible a emancipación para caracterizar la humanización desde nuestra América, expresión identitaria de la transmodernidad en la tierra que habitamos.
} 
específica. Reproduciendo cada "nosotros" su vida en su propio ghetto y "tolerando" a los otros, los equilibrios que hacen posible a la humanidad se asegurarían.

La exacerbación del autocentramiento multiculturalista y por lo tanto de la fragmentación posmoderna, que es experiencia globalizada de la vida contemporánea, presenta inequívocas señales de que el multiculturalismo como orientación, solamente puede profundizar la crisis de la humanidad que el monoculturalismo ha prohijado.

El "nosotros transmoderno" es una trascendentalidad al interior del "nosotros nuestroamericano”, pues éste último es una determinación territorialmente situada de aquél.

Como el "nosotros nuestroamericano" también el "nosotros transmoderno" es tópico y utópico desde 1492, y también como aquél es constitutivamente "intercultural".

Esto es, la "interculturalidad" no es para él una posibilidad a ser libremente elegida como alternativa, sea a la "monoculturalidad", sea a la "multiculturalidad" -que son las caras culturalmente complementarias de la modernidad y la posmodernidad hegemónicas-, sino una necesidad inherente a la condición dinámica, pluralista, abierta a las alteridades, incluida la naturaleza, que como "Madre Tierra" es sujeto de dignidad superior, pero no es un ídolo, pues sin su afirmación no es posible afirmar al ser humano como ser supremo, pues este es también naturaleza y sin ella no puede vivir.

Es constitutivo del "nosotros transmoderno" por la mediación del "nosotros nuestroamericano" que es su específica manifestación en nuestras latitudes, el pathos, el ethos y el logos intercultural, por el que se articulan diferencias con la cancelación de asimetrías. Esa es su identidad.

Compartimos con Catherine Walsh que

Interculturalidad tiene una significación en América Latina y particularmente en Ecuador, ligada a las geopolíticas de lugar y espacio, a las fechas históricas y actuales de los pueblos indígenas y negros, y a sus construcciones de un proyecto social, cultural, político, ético y epistémico orientado a la descolonización y a la transformación (WALSH, 2014, p. 17).

Pero sin negar el protagonismo de "las luchas históricas y actuales de los pueblos indígenas y negros" en la construcción de esa significación de interculturalidad, esa referencia debe trascenderse hacia todos los "otros" - pueblos indígenas y negros incluidos-, que se reconocen, afirman, organizan y activan en perspectiva de la cancelación de todo tipo de asimetrías.

Las asimetrías vigentes se generan desde la matriz moderno-posmoderna-colonialoccidental. 
En relación a ellas, las luchas históricas y actuales de los pueblos encuentran en "luchas históricas y actuales de los pueblos indígenas y negros" la última instancia en el desmontaje crítico de la modernidad - posmodernidad - colonialidad - occidentalidad.

Sin la liberación de los pueblos indígenas y negros no hay liberación de los pueblos, y sin la liberación de los pueblos, no hay liberación de los pueblos indígenas y negros.

También compartimos con Catherine Walsh que

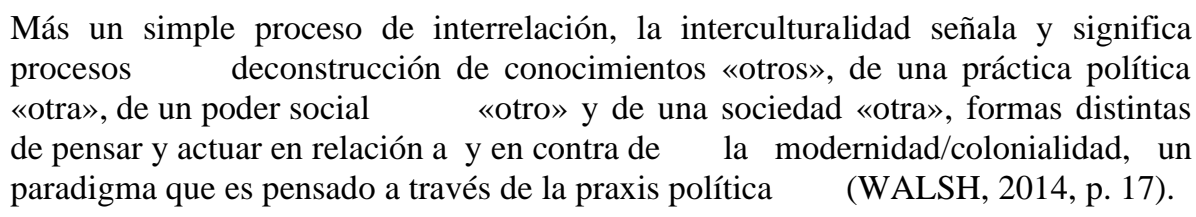

Profundizando esta idea, la interculturalidad consiste en un conjunto de procesos históricos, sociales, culturales y políticos-, por el cual un "nosotros" "otro" respecto a la modernidad-posmodernidad- colonialidad-occidentalidad, que categorialmente puede señalarse como "nosotros" o "sujeto" transmoderno se constituye.

Acordamos también con que la interculturalidad de la que se trata no proviene de "una institución académica" sino de movimientos sociales -o comunitarios- en los que lo "étnicosocial" es una última instancia de referencia en la orientación de sentido, pero no un límite para dejar fuera de la constitución intercultural a interlocutores del campo social popular provenientes de matrices étnicas otras que "los pueblos indígenas y negros".

Que el criterio, última instancia o la orientación radical de sentido transformador de la agencia intercultural pueda radicar - de hecho y de derecho- en particular en Ecuador y en general en América Latina, en "los pueblos indígenas y negros", no debe querer decir que la interculturalidad como proceso de constitución de todas esas otredades a que se ha hecho referencia que hacen a la transmodernidad, pueda o deba excluir otros sectores del campo social popular - constituido por todos aquellos que padecen asimetrías, que además de los pueblos indígenas y negros, incluye a las mayorías de los mestizos y los blancos.

Justamente en el grado en que unos y otros "sientan" (pathos), "actúen" (ethos) y "piensen" (logos) interculturalmente, reconociéndose y organizándose, podrán activarse como sujeto político popular contrahegemónico, para transformar estructuralmente no solamente el campo del pensamiento, sino el campo del poder por la construcción de una hegemonía, radicalmente nueva por la lógica intercultural de su construcción, que será la hegemonía intercultural transmoderna alternativa a la hegemonía monocultural-multicultural de la modernidad-posmodernidad colonial occidental. 
La superación de Occidente como condición de posibilidad para que todos en su diversidad -la naturaleza incluida- puedan vivir.

Ese otro mundo que es posible y necesario, -cuya clave es intercultural/transmoderna, porque este mundo - monocultural/multicultural moderno/posmoderno- es imposible.

\section{Conclusiones}

No solamente teniendo una orientación explicita a elucidar y constituir sujeto, transmodernidad e interculturalidad estaremos aportando -sea desde las humanidades que practicamos en el campo de la investigación o desde las humanidades de las que somos parte en las sociedades complejas que integramos, o desde la fecunda articulación entre ambas - a la "conflictiva y nunca acabada constitución de humanidad"11.

Desarrollando nuestras investigaciones desde un pathos arraigado en nuestra realidad y por lo tanto sensible a los problemas que nos atraviesan como "humanidades" y en el marco de un ethos orientado desde la radicalidad de ese pathos a discernir situaciones y relaciones deshumanizantes no válidas pero vigentes en lo instituido, con la mediación de las disciplinas humanísticas en que nos hemos formado, podremos seguir realizando "estudios humanísticos" en términos de un logos vertebrador de una "ciencia con consciencia" -recordando un título de Edgar Morin (MORIN, 1984) cuyos aportes explicativos e interpretativos puedan ser fecundos en la transformación del mundo en perspectiva instituyente sobre la referencia de la humanización del ser humano que consiste en su liberación o liberación del ser humano que consiste en su humanización. ${ }^{12}$

\section{Referencias}

DUSSEL, E. 1492 El encubrimiento del otro. El origen del mito de la modernidad, Santafé de Bogotá, Ediciones Antropos Ltda., 1992.

\footnotetext{
${ }^{11}$ Esta expresión recrea resignifícándolo el título del magnífico libro de Norbert Lechner La conflictiva y nunca acabada construcción del orden deseado (LECHNER, 1984), que no ha dejado de estar presente en nuestras reflexiones e investigaciones por su valor heurístico para referirnos a distintos aunque convergentes problemas.

12 Escribe Hinkelammert en una caracterización del pensamiento crítico que compartimos: "La crítica del pensamiento crítico la constituye un determinado punto de vista, bajo el cual esa crítica se lleva a cabo. Ese punto de vista es el de la emancipación humana. En este sentido es el punto de vista de la humanización de las relaciones humanas mismas y de la relación con la naturaleza entera. Emancipación es humanización, humanización desemboca en emancipación" (HINKELAMMERT, 2007: 278). Esta caracterización del pensamiento crítico, aplica perfectamente tanto al pensamiento de "la razón universitaria" como al de "la razón campestre" de que hablaba Martí. También, dentro de la primera a las "disciplinas humanísticas" o "humanidades". Esa es la especificidad de la crítica a que deben responder las "humanidades" en cuanto disciplinas analítico - crítico - normativas. En el cierre de nuestra conclusión, siguiendo el discernimiento de Dussel que antes hemos consignado entre "emancipación” y "liberación”, sin traicionar el espíritu de la fórmula de Hinkelammert, sino en acuerdo con el discernimiento de Dussel, respetando en toda su profundidad de sentido ese espíritu, es que hablamos de "liberación" allí donde Hinkelammert habla de "emancipación".
} 
FERNÁNDEZ, E. "La problemática de la utopía desde una perspectiva latinoamericana”, en Proceso civilizatorio y ejercicio utópico en nuestra América, Arturo Andrés Roig (Compilador), San Juan, Argentina, EFU, 1995, p. 27-47.

HINKELAMMERT, F. Crítica a la razón utópica, San José de Costa Rica, DEI, $2^{a}$ ed., 1990, p. 19-29.

HINKELAMMERT, F. La fe de Abraham y el Edipo occidental. San José de Costa Rica, DEI, $2^{a}$ ed., 1991.

HINKELAMMERT, F. El sujeto y la ley. El retorno del sujeto reprimido, Heredia, Costa Rica, Editorial Universidad Nacional (EUNA), 2003.

HINKELAMMERT, F. Hacia una crítica de la razón mítica. El laberinto de la modernidad, San José de Costa Rica, Editorial Arlekín, 2007.

HINKELAMMERT, F. Totalitarismo del mercado. El mercado capitalista como ser supremo, México D.F., Colección Inter Pares, Akal, 2018.

KANT, I. Fundamentación de la metafísica de las costumbres, Madrid, Colección Austral, $3^{\text {a }}$ edición, Espasa Calpe, 1967.

LECHNER, N. La conflictiva y nunca acabada construcción del orden deseado, FLACSO, Ediciones Ainavillo, Santiago de Chile, 1984.

MARTÍ, J. "Nuestra América", en Obras escogidas en tres tomos, La Habana, Editora de Ciencias Sociales, 1992, p. 480-487.

MARX, K. "Crítica a la Filosofía del Derecho de Hegel”, en La cuestión judía ( y otros escritos), Barcelona, Planeta - Agostini, 1994, p. 67-85.

MORIN, E. Ciencia con consciencia, Anthropos, Barcelona, 1984.

ROIG, A. Teoría y crítica del pensamiento latinoamericano, México D.F., Fondo de Cultura Económica, 1981.

RODRÍGUEZ, P. "Nuestra América" contra la lógica de la modernidad. Apuntes para un estudio", La Habana, inédito, Centro de Estudios Martianos, 2010.

ROIG, A. "El discurso utópico y sus formas en la historia intelectual ecuatoriana", Estudio introductorio a La utopía en el Ecuador, Quito, Biblioteca Básica del Pensamiento Ecuatoriano, 25, Banco Central del Ecuador, Corporación Editora Nacional, 1987, p. 13-97.

SAMBARINO, M. Investigaciones sobre la estructura aporético-dialéctica de la eticidad, Montevideo, Facultad de Humanidades y Ciencias, Universidad de la República, 1959.

WALSH, K. "Interculturalidad y colonialidad del poder. Un pensamiento y posicionamiento otro desde la diferencia colonial. Álvaro García Linera, Walter Mignolo y Katherine Walsh Interculturalidad, descolonización del Estado y del conocimiento, Buenos Aires, Ediciones Del Signo, 2a ed., 2014, p. 17-51. 